\section{Military Technical College Kobry El-Kobbah, Cairo, Egypt.}

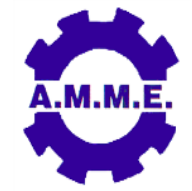

$17^{\text {th }}$ International Conference on Applied Mechanics and Mechanical Engineering.

\title{
AN AUTOMATED HARD-POINTS VISION TEST OF A NEW-CONCEPT CAR
}

\author{
H.M.A. Hussein ${ }^{* *}$, A. Mahrous**, M. Elsayed ${ }^{*}$ M. Ebrahim*, M. Zakey ${ }^{*}$, M.Fathy*, \\ M. Abdein*, H. Othman*, A. Faragallah* and M. Soliman*
}

\begin{abstract}
Hard-Points are a collection of rules governing the automotive shape and movement in the streets. These rules are prepared by the most famous car manufacturers in the world, and modified year by year. Those rules apply on the car after complete preparing the digital model. There are about 190 rules covering all the car contents. Vision test rule is one of the most important Hard Points rules, which is made by plotting the new-concept car digital model in 2D. This paper discusses one of the SolidWork customization techniques to visualize the Hard Points vision test in 3D. This proposed technique is prepared as one of a group of efforts and developments to automate the Hard-Points test to save the consumed time by the car designers.
\end{abstract}

\section{KEY WORDS}

Automotive new concept, Hard-Points, Solidworks, Vision test,

* Graduate student, Dept. of Mech. Eng., Helwan University, Cairo 11732, Egypt.

** Assist prof., Dept. of Mech. Eng., Helwan University, Cairo 11732, Egypt. 


\section{INTRODUCTION}

Hard points are a collection of rules made to control the car design and motion on roads. Those rules are prepared by experts in car design from the most famous car industry in the world. Many years ago, each car manufacturer has its own designs characters such as Volkswagen "Beetles", Peugeot and Renault. The big vision in this period was to give each car brand its own character. This manufacturing vision gives weakness to those types of cars. Latter, the new car styles occupied more and more customers from the market. This leads to study the design of those new styles of cars. FIAT [1] was one of the pioneers car manufacturing companies who paid more attentions to the rules which gives the customers the safety and comfort. They convert this study into science. The title of this science or rules was known later as "Hard Points".

After applying the hard point's rules, we can find similarities in car design shapes. The hard point's rules include all the factors, which handle the car design from inside and outside, such as lightening, vision test, ergonomics, and many other tests. There are about 190 test rules that could be found under the hard point's rules title. Those 190 rules are categorized under many groups which represent the car complete design, such as; visibility, shock-bumpers, body, Port-doors, Front bumpers, Grille, tailgate, spoiler, envelope wheel and others. Not all of the 190 test rules apply for each car design, as some of them are suitable for environments and countries cultures and country traffic rules, which are not suitable for others, such as hot "countries, and cold countries", "forests and deserts",...etc.

Global Car Manufacturers Information Exchange Group, "GCIE", is an annual meeting made by the famous car manufacturers in the world. GCIE2004 was held in (FIAT-Alfa Romeo), GCIE2005 was held in (BMW), GCIE2006 [2] was held in (Jaguar), GCIE2007 was held in (Porsche/Weissach), and GCIE2008 [3] was held by (Renault and Daimler Chrysler). In this annual meeting, new recommendations and car designs are published as a reference for the car designers in all the car factories and consulting offices around the world. In these all meetings, they discuss details related to the car manufacturing starting from the suggested language used in designs to countries traffic rules. The recommendations made by those meetings are used as Standards in new concept car designs.

Vision test is one of the hard points test rules, as the driver must scan by his eyes and by mirrors most of the areas around him. (1) Vision - Forward Up at vehicle centerline (as shown in Fig.1) is measured at car centerline with eyellipse projected to car centerline. The minimum angle from the horizontal to a line tangential to the top of the SAE "Society of Automotive Engineering" 95th percentile eyellipse and to the front upper trimmed body, excluding inner mirror, glass mounted hardware, attachments, and DLO "Daylight Opening". (2) Vision - Forward Down at centerline of Vehicle is measured at car centerline with eyellipse projected to car centerline. The minimum angle from the horizontal to a line tangential to the bottom of the SAE 95th percentile eyellipse and to the first obstructing component (hood. DLO. Dashboard, etc ..) excluding wiper. (3) Vision - Rearward Up at centerline of Vehicle is measured at car centerline with eyellipse projected to car centerline. The minimum angle from the horizontal to a line tangential to the top of the SAE 95th percentile eyellipse and to the first obstructing component on the rear upper trimmed body or 
DLO, including Brake light, Centre High Mount Stop Lamp (CHMSL) A negative value indicates restricting component is lower than the top of the eyellipse. For UltraCommercial Version, (UCV), if the pillars of rear swing doors are obstructing the vision at car centerline, the maximum dimension should be measured at the plane $Y=$ centerline of driver. (4) Vision - Rearward Down at centerline vehicle measured at car centerline with eyellipse projected to car centerline.

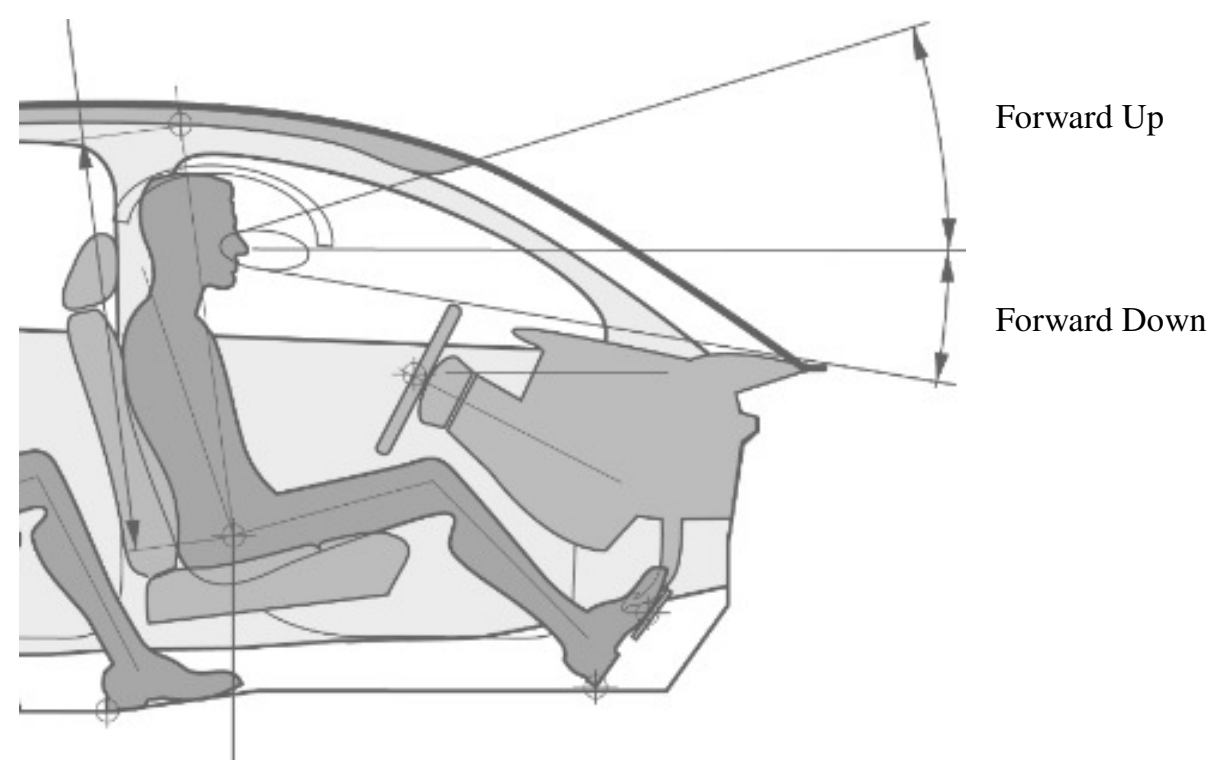

Fig. 1. The Forward vision possibility of the driver [4].

The minimum angle from the horizontal to a line tangential to the bottom of the SAE 95th percentile eyellipse and to the first obstructing component at the rear, including DLO and the rear end head restraint (if base), but excluding wiper. A negative value indicates restricting component is higher than the bottom of the eyellipse. For UCV, if the pillars of rear swing doors are obstructing the vision at car centerline, the maximum dimension should be measured at the plane $Y=$ centerline of driver. (5) vision-Forward Up at "Center Line of Occupant" (CLO) The angle from the horizontal to a plane tangent to the top of the SAE 95th percentile eyellipse and to the upper trimmed body, including all the elements that can obstruct the vision (sun visor, design glass outline, etc ... ), measured at CLO driver Y plane.

\section{SOLIDWORK CUSTOMIZATION}

Recently, SolidWork software [5] is one of the most promising CAD systems; it is light software not heavy or complicated such as CATIA, CREO, or Uni-Graphic. It's Userfriendly, and has a lot of advanced CAD facilities, such as sheet metal folding and unfolding....etc. It is directly connected to Finite Element Analysis software's such as ANSYS. The customization of SoildWork is a powerful tool, which gives the knowledge of the engineering application together with the merits of the CAD in SolidWork. There are many applications of using Solidwork customization with engineering applications, such as "LogoPress [6]" and "3D-QuickPress [7]" in case of Progressive Dies. The Application Programming Interface "API" is one of Solidworks customization tools. It is a way to automate and customize the product. Solidworks API contains many functions that we can call it from: Visual Basic for 
Applications (VBA), Visual Studio Tools for Applications (VSTA), VB.NET, Visual C\#, Visual $C_{++} 6.0$.

For the vision test under SolidWork, the customizing level is used. First, the "Camera" tool is used Fig. 2, after selection of the dummy head, which represent the driver. Second, "aimed at target" is selected after defining 2 points. As shown in Fig. 3. The first point "Target by selection". This point, which defines the vision scope from the driver side. i.e. the point on the road on a defined distance.

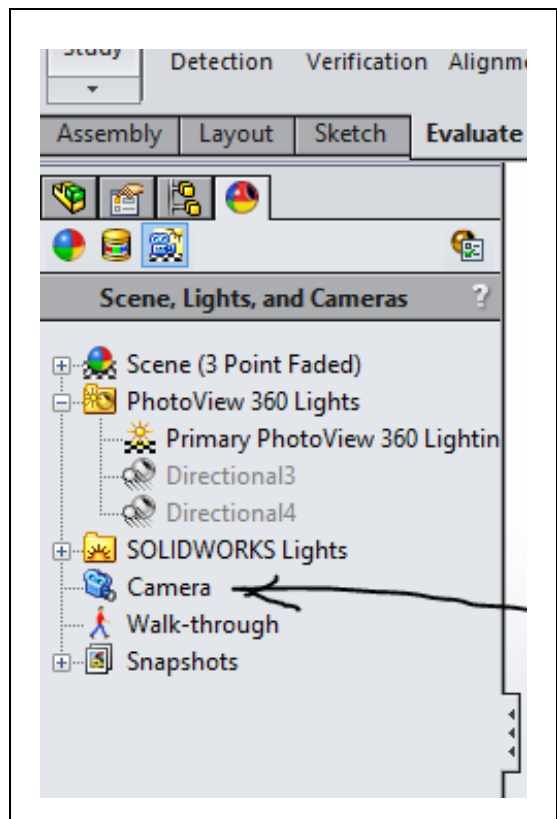

Fig. 2. The Camera side menu.

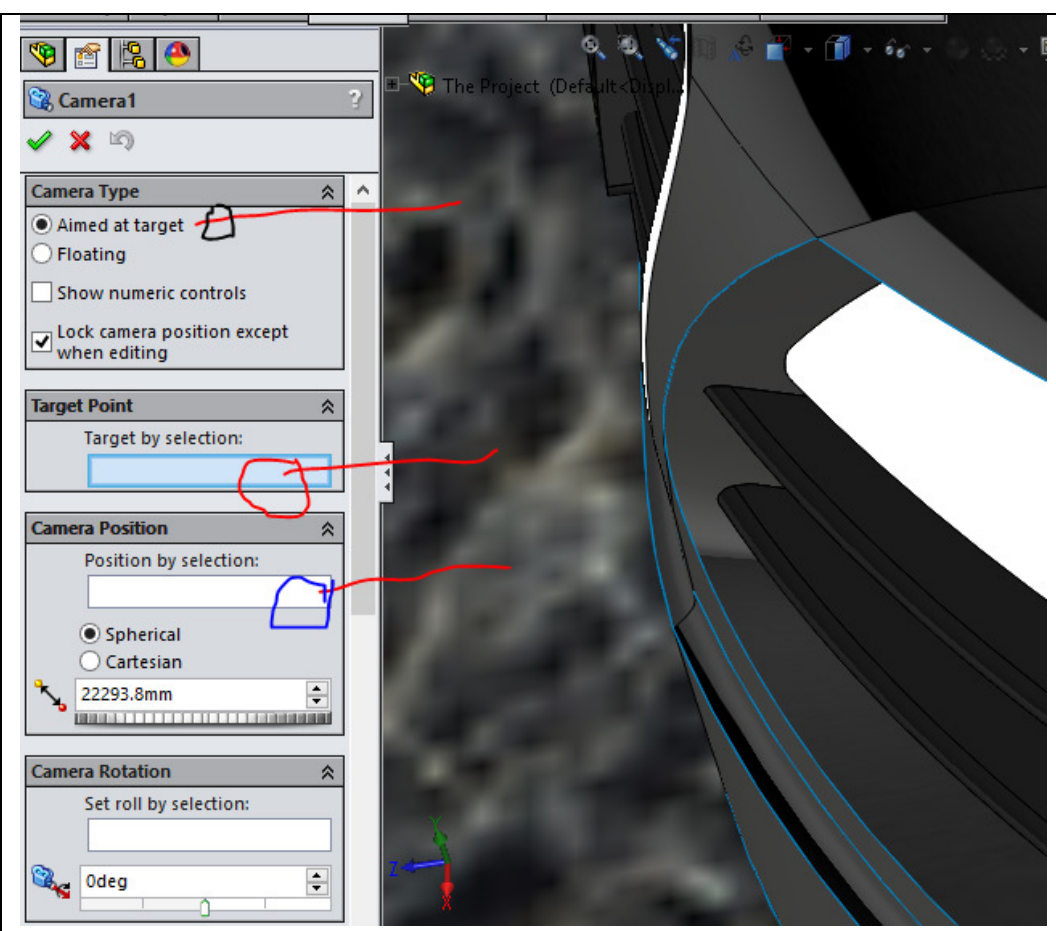

Fig. 3. The camera interface inside SolidWork.

The second point "position by selection", is the point that represents the driver eye from his position on the driver seat. We suppose a dummy one the driver seat inside the "assembly project". Those points are defined approximately by their geometries. For the "target point", it is better for non-fixed type which clears the vision scope and the facility of rotation and angle change.

\section{CUSTOMIZED VISION TEST}

Based on the previous described technique, once the user has defined the 2 points, the side window will show the vision in front of the driver from inside the designed new concept car. The visibility will be for the selected distance by the second point. The following figures shows the position of the "aimed at target" point and its related vision window, which represent the proposed vision test. Figure 4 shows the test at distance of 6 meters. Figure 5 shows the vision test at a distance of 8 meters. 


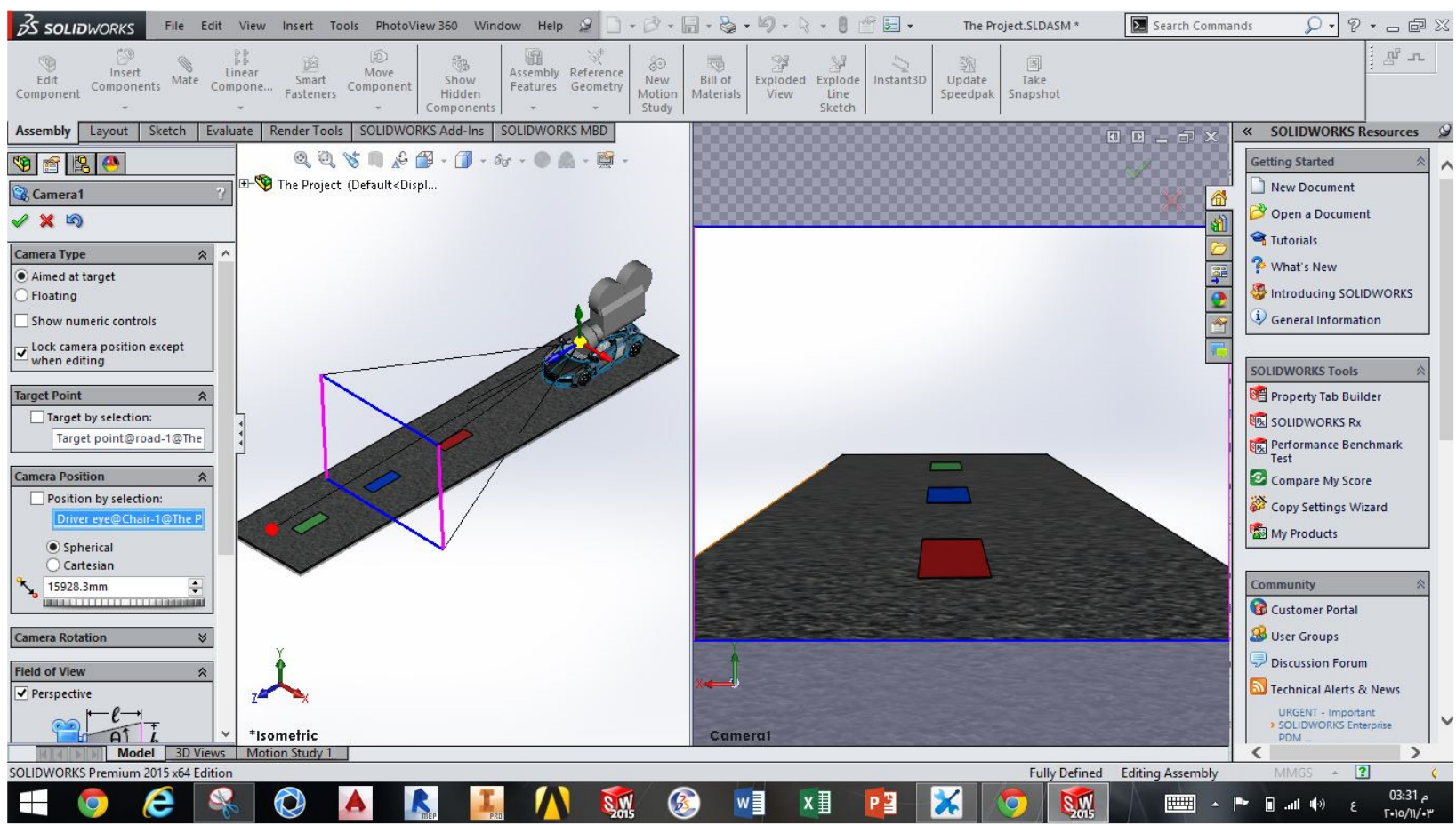

Fig. 4. The vision test at a distance of 6 meters.

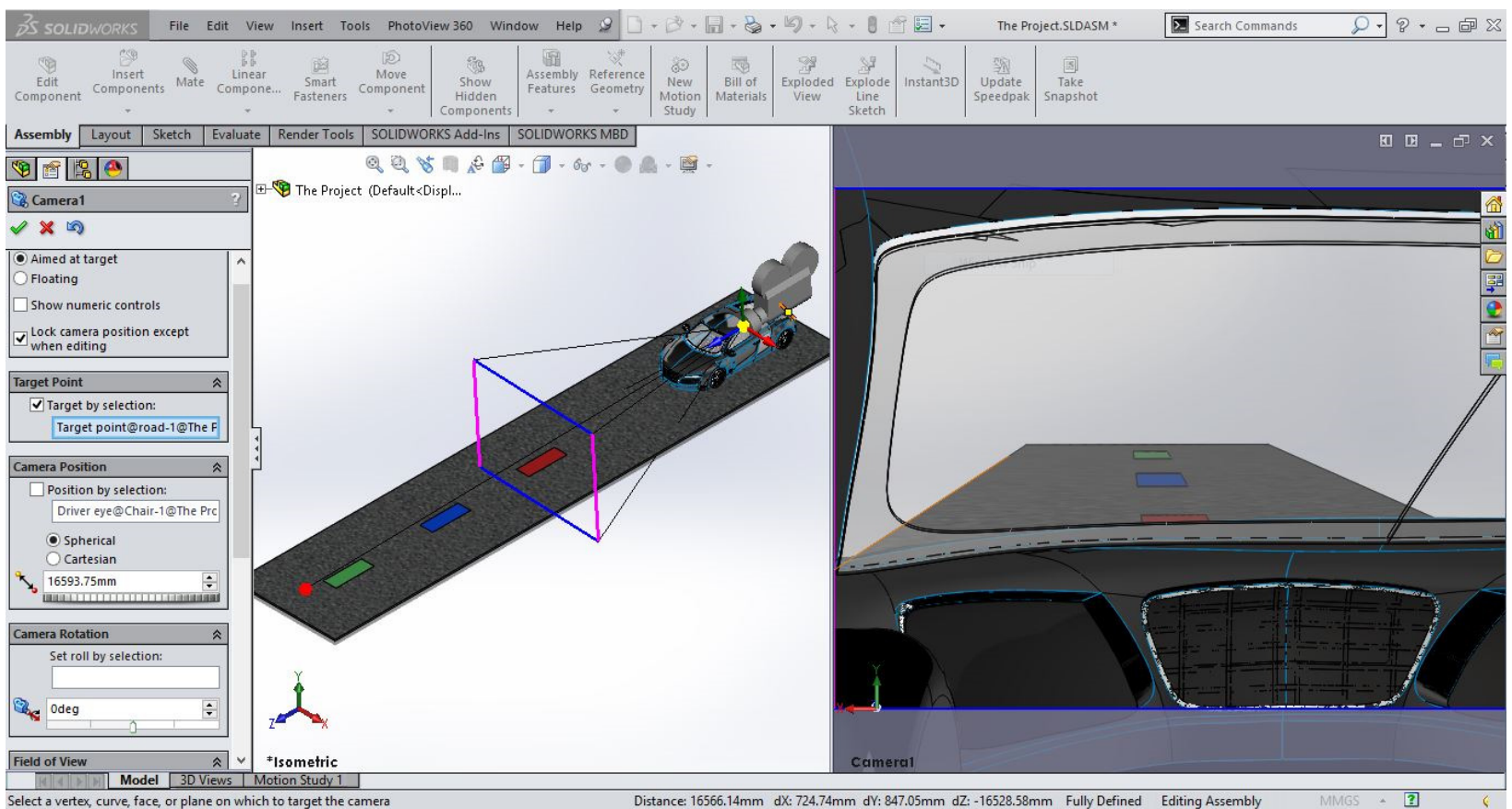

Fig. 5. The vision test at a distance of 8 meters.

By the same way, the proposed technique can recognize any vision from the inside of the car for any direction forward or backward as mentioned in the GCIE recommendations. For the inclined vision test, this test cannot be achieved by the traditional 2D plotting technique. In the proposed technique under SolidWork, in any angular direction, the driver vision could be categorized. Fig. 6 represents the vision test with inclined angle to the right, and Fig. 7 represents the vision test with inclined angle to the left. 


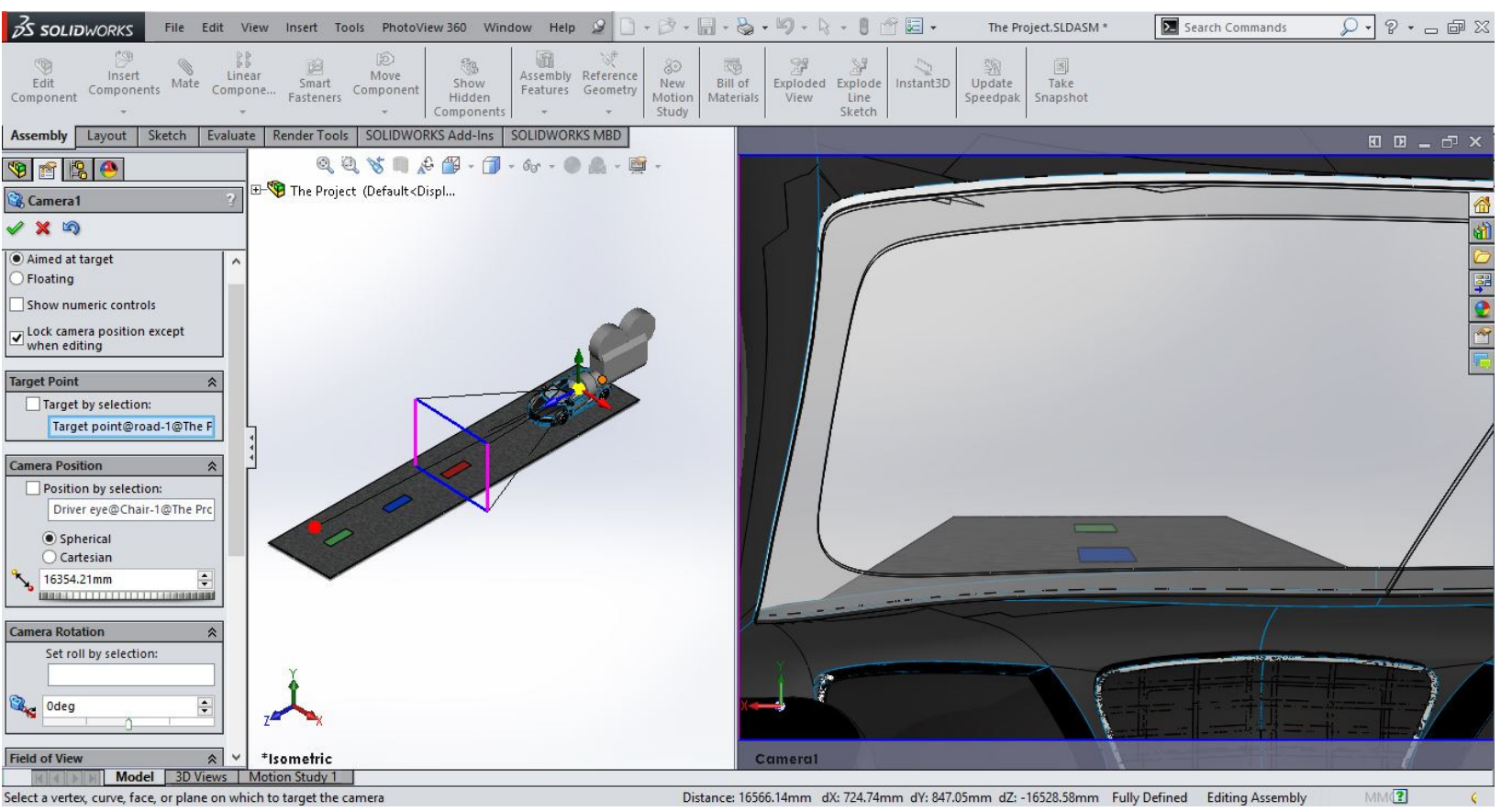

Fig. 6. The vision test with inclined angle to the right.

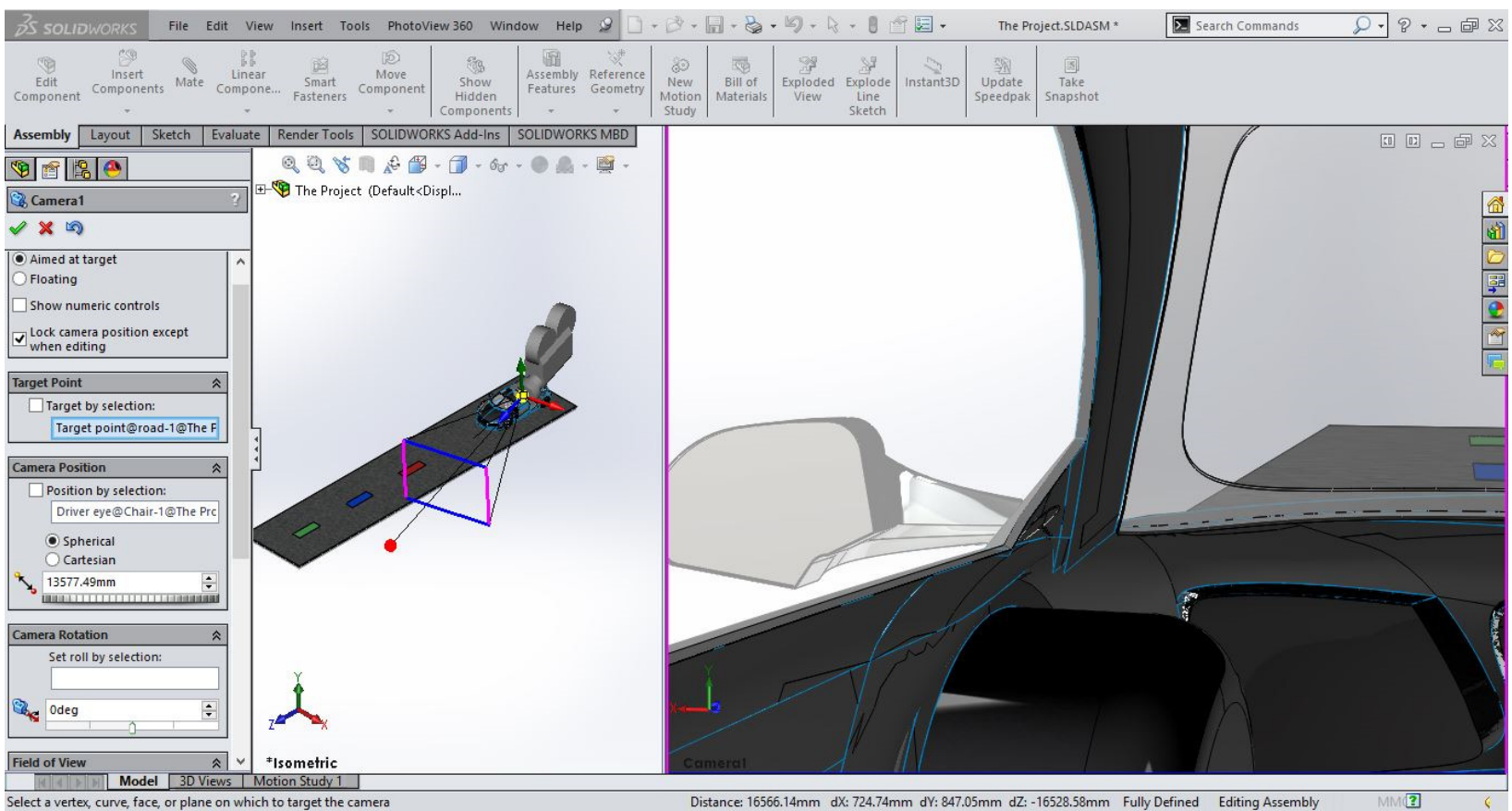

Fig. 7. The vision test with inclined angle to the left.

It's clear in Fig. 7 that the A-Pillar will prevent the vision of the driver, and there is a considerable dead zone. Another challenge can be produced by this technique, is the partial vision inside the car itself, with partial vision for the road. This facility could be shown in Fig. 8. 


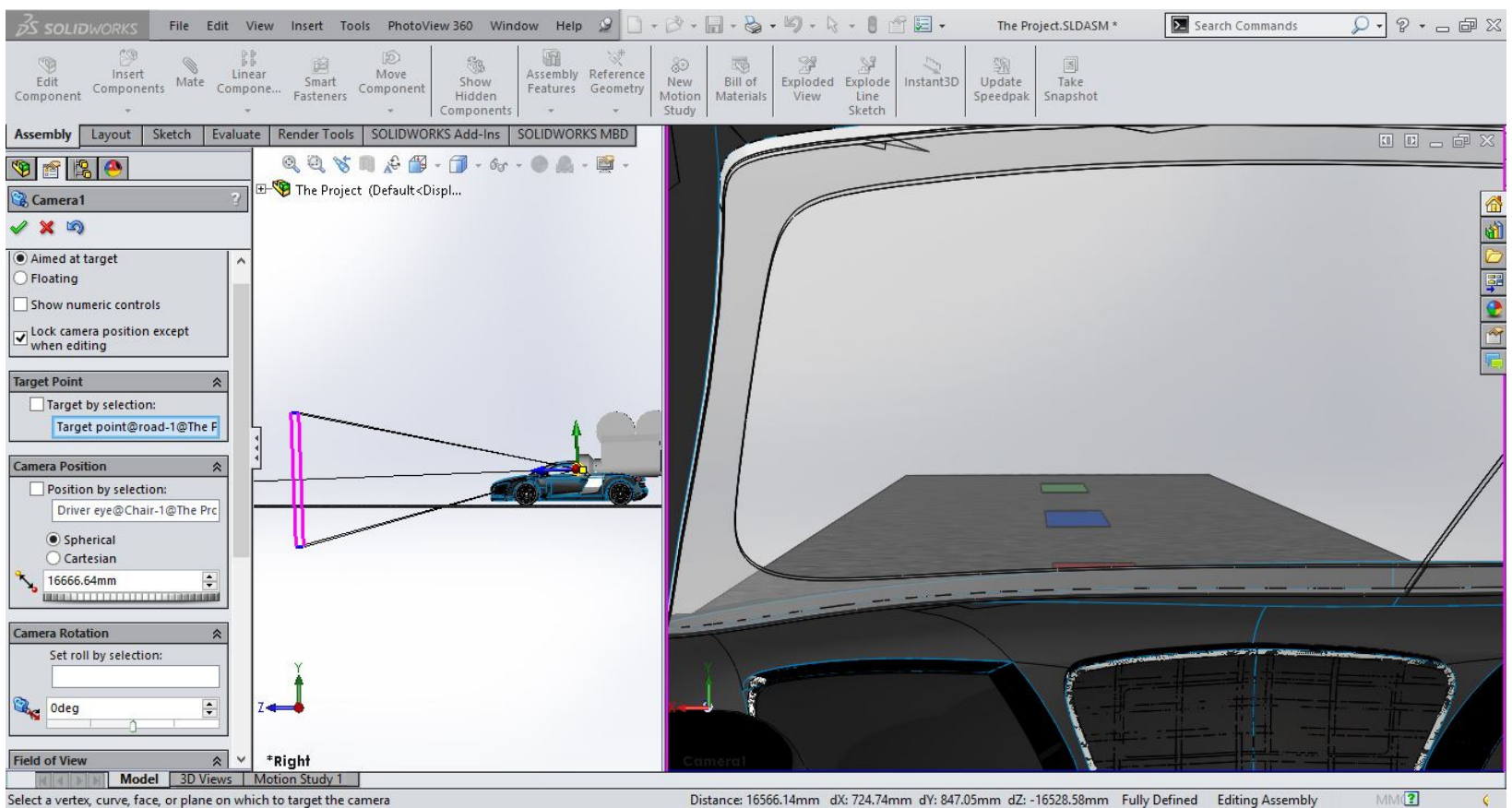

Fig. 8. The vision test fot the dashboard (inside the car itself).

\section{CONCLUSIONS}

Automation of Hard-Point tests is a new idea which is discussed in this paper. The new technique customizes the Soliwork to produce this test facility. This technique will save the new concept car designers time and efforts from plotting the car in $2 \mathrm{D}$ dimension for testing the vision. More Hard Points tests could be controlled under this technique, more time and efforts savings are obtained.

\section{REFERENCES}

[1] G. Genta, L. Morello, F. Cavallino - L. Filtri, "The Motor Car Past, Present and Future”, Mechanical Engineering Series, Springer Verlag, 2014.

[2] GCIE2006, annual car manufacturer meeting, Part 3; description of the package drawing and dimensions list, Jaguar, (June 2005).

[3] GCIE2008, annual car manufacturer meeting, Renault, (January 2008).

[4] S. Macey, and G. Wardle," H-Point, The fundamentals of car design and packaging", art center college of design, design studio press, first edition, April (2009).

[5] SolidWork2010

[6] LogoPress. Powlly les Vignes, France, www.logopress3.com.

[7] 3DQuickPress, HonkHong, www.3DQuickpress.com. 